\title{
Reducing Short Circuit Level in 400kV Iraqi Grid System by Using FACTS Device
}

\author{
Inaam I. Ali ${ }^{1}$, Mohanad Sh. Tarad Al-Aasam ${ }^{2}$ \\ ${ }^{1}$ University of Technology, Electrical Engineering Department, Iraq, Baghdad. \\ ${ }^{2}$ University of Technology, Electrical Engineering Department, Iraq, Baghdad. \\ in2006aam@yahoo.com,tr_sh_mo2007@yahoo.com
}

\begin{abstract}
Electrical power systems are different in their sizes because of their amount of generation power stations, substations, transmission lines and loads. Therefore, these factors may impact on short circuit levels values. Capacity of power stations and dummy transmission lines in Extra high voltage grid $(400 \mathrm{kV})$ of the Iraqi Electrical power grids cause high short circuit levels values such that exceed both rating of the peak and breaking capacity of switchgear equipment's. Reduction of short-circuit levels by using Fast-acting Flexible Alternating Current Transmission Systems (FACTS) types devices in power grids maintain the operation of power grids with acceptable value of short circuit levels for their electrical equipment's and preventing cascading event outages which may lead to blackouts. This paper mainly studies strategies on how to add Short Circuit Current Limiter (SCCL) device by determining its number, value and location of connection in power grids by programing with (PSS ${ }^{\mathrm{TM}}$ E version 30.3 Package Program). IEEE 25-bus system is used for testing the adding series SCCL at power transmission lines method procedure. The results of adding series SCCL with power transmission lines give significant reducing short circuit levels for the stations have highest short circuit levels in order to prevent the blackouts of overall power grid.
\end{abstract}

\section{Index Terms-Flexible Alternating Current Transmission Systems (FACTS) devices, Station Busbar of Highest Short Circuit Level (SBHSCL), Thyristor Protected Series Compensation (TPSC) and Super Conducting Current Limiter (SCCL).}

\section{INTRODUCTION}

There are three types of power systems

a) Meshed systems: possess load flow problems.

b) Weak systems: possess stability problems.

c) Strong systems: possess high fault currents problems.

Short Circuit Current Limiter or Super Conducting Current Limiter (SCCL) is the solution for the strong electrical power systems problems. Grid Power Flow Controller (GPFC) is the solution for the meshed and weak electrical power systems problems. This paper concentrates on the solutions for strong systems problems of high fault currents [1-3].

The main properties of Fault Current Limiters (FCL) are having variable-impedance device connected in series with a circuit such that have a large value at fault to limit fault current and a very low impedance during normal condition. The impedance of FACTS device must have low value because of the risks of voltage collapse. Access the system voltage to voltage collapse may lead to blackouts because of synchronizing gradient of post-fault condition voltage with higher short circuit levels [4-5]. During normal operation, any increase in reactance leads to increase the voltage drop of the reactor in the network. The important issue is choosing a location of FACTS device [6-7]. 


\section{II. [FACTS] DEVICES THEORETICAL PRINCIPLES}

Dynamic controlling of operating voltage, line impedance and operating phase angle of high voltage AC lines are important problems for solving by using FACTS devices. Fig. 1 shows a power transfer between two points or busbars ( 1 and 2$)$, which depends on factors or variables voltage $\left(U_{1}\right.$ and $\left.U_{2}\right)$, reactance $(\mathrm{X})$ between two points or busbars and stability angles $\left(\boldsymbol{\delta}_{1} \& \boldsymbol{\delta}_{2}\right)$. These factors are used in "(1)",which has three parts (parallel, series and load flow continuous). Types of FACTS devices are determined according to these parts. This paper concentrates on the series part and its effect on reducing short circuit levels of electrical power system [8-9].

$$
\mathbf{P}=\frac{\mathbf{U}_{1} \mathbf{U}_{2}}{\mathrm{X}} \sin \left(\boldsymbol{\delta}_{1}-\boldsymbol{\delta}_{2}\right)
$$

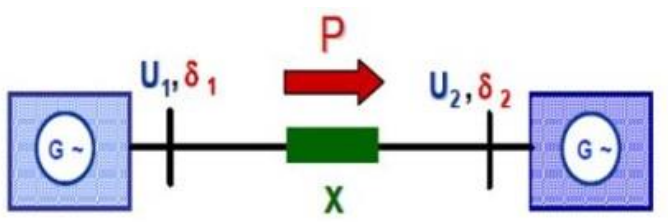

FIGURE 1. THE POWER FLOW BLOCK DIAGRAM

\section{A. Thyristor Protected Series Compensation TPSC:}

Figure 2 shows the fast cool-down time, which is an outstanding feature for this thyristor protected series compensation (TPSC). It can be seen that the TPSC will be ready for additional contingencies, such as multiple fault conditions, before the end of the Auto-Reclosure dead time [10].

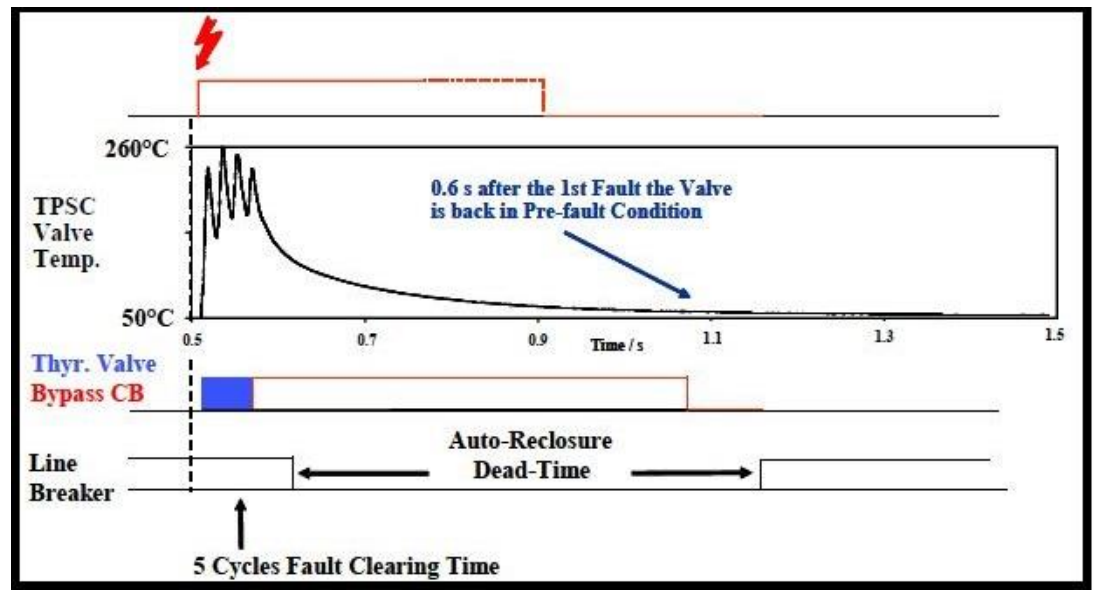

Figure 2. Benefits of TPSC - Full AVAilability AFter FAult Clearing Time [10].

\section{B. Super Conducting Current Limiter (SCCL)}

The cool-down time with very fast time and peak current of $110 \mathrm{kA}$ capability are the main features of high power light-triggered thyristors. The SCCL device is an external reactor combines with TPSC as seen in Fig.3. The series reactor may reduce the short-circuit current level. At steady-state conditions, SCCL operates with zero impedance, and high impedance at the short-circuit case, as seen in Fig. 4. A few milliseconds spend of switching for limiting reactor impedance [10-13]. Limiting short-circuit in a large power grid by using SCCL device impact on the transient stability of the overall grid [14-17].

Reducing transmission angle by using series compensation for long AC lines may provide stability enhancement. Fixed Series Compensation (FSC) is the simplest form of series compensation $[1,7,18]$. Preventing faults cannot be done by FACTS devices, but can mitigate the impacts of faults. By reducing number of transmission line trips may make electricity supply more secure $[7,12,19]$. The dynamic 
behavior of splitting strategies and adding series current limiting reactor methods for reducing short circuit levels are limited compared with adding FACTS device for the power grid but less expensive $[6,15]$. By using SCCL, reactive power remains balanced, with no impact on grid load flow, no impact on first swing stability and no risk of voltage collapse [18,20].

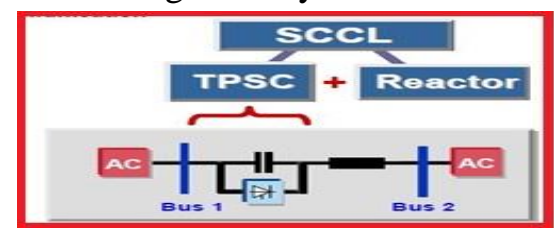

FigURE 3. SCCL CiRCUIT DIAGRAM.

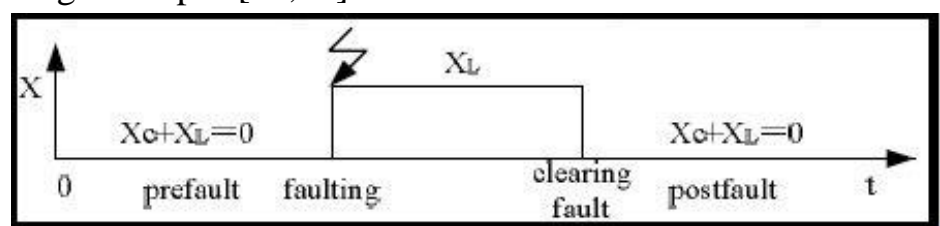

Figure 4. Static CHARACTERISTICS(C/C) OF SCCL.

\section{Approperate location of FACTS device connection}

Some stations busbars have restricted short circuit levels is the main problem of the Iraqi power grid. Extra High or high voltage circuit breakers mean life impact by higher short circuit levels values specially at interrupting process. These values of short circuit levels may lead to damage that circuit breakers and cascading accidents occurs then may lead to blackouts. The appropriate location of FACTS device installation is in series with the power lines which have high short circuit current feeding faults at the Station Busbar of Highest Short Circuit Level (SBHSCL).

\section{The algorithm of adding FACTS device}

The procedure of the proposed method can be seen in Fig. 5, and details as follows: -

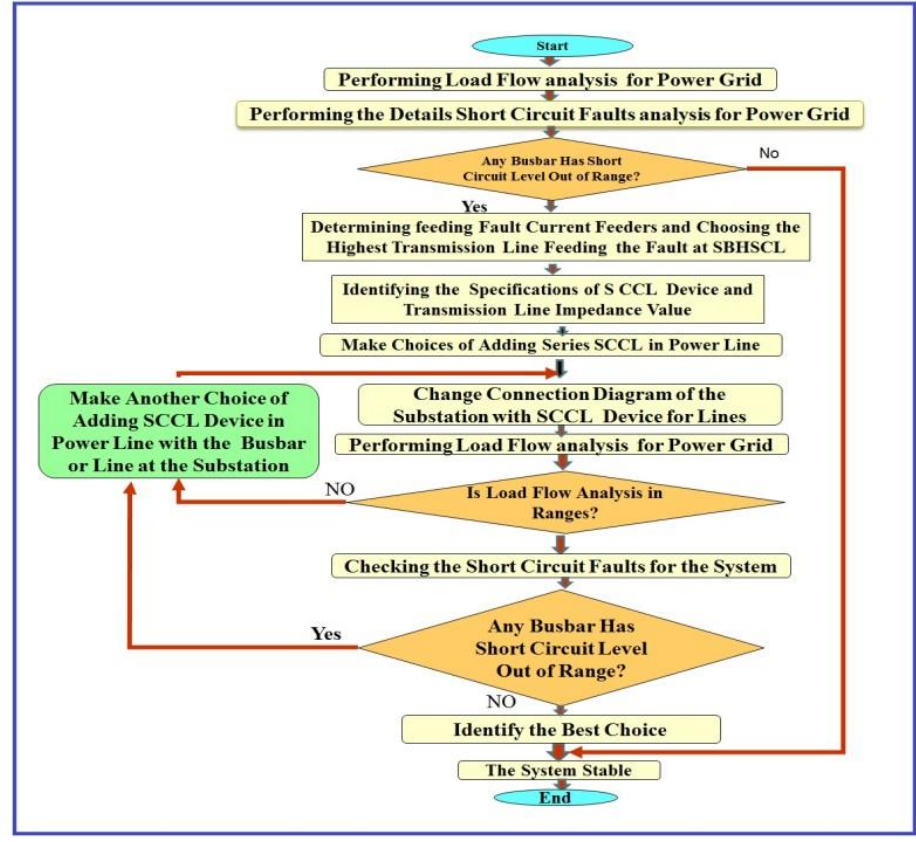

FIGURE 5. FLOWCHART OF ADDING FACTS DEVICE STRATEGIES

a) Checking load flow analysis for the power system.

b) Checking the details of short circuit levels of the system busbars.

c) Identifying Station Busbar of Highest Short Circuit Level (SBHSCL), which have the highest short circuit levels that exceed or near maximum values of the equipment.

d) Obtaining a table for currents feeding fault in each busbar during the fault, showing the flow diagram with load flow of the (SBHSCL) and determining the FACTS device connection in series with power lines, which have the highest short circuit level at the (SBHSCL) side to get the optimum choice. 
e) Checking load flow and short circuit analysis for each choice and determining the successful choices.

f) Making a table for all choices implemented in item d.

g) Drawing curves for all choices.

h) Identifying the best choice, which has minimum number of SCCL devices and the highest reducing short circuit levels for(SBHSCL) and other substations in the power grid.

\section{CASE STUDY}

- Case (1): Test System: Fig.6 shows simulation IEEE 25-bus system for implementation of the proposed method.

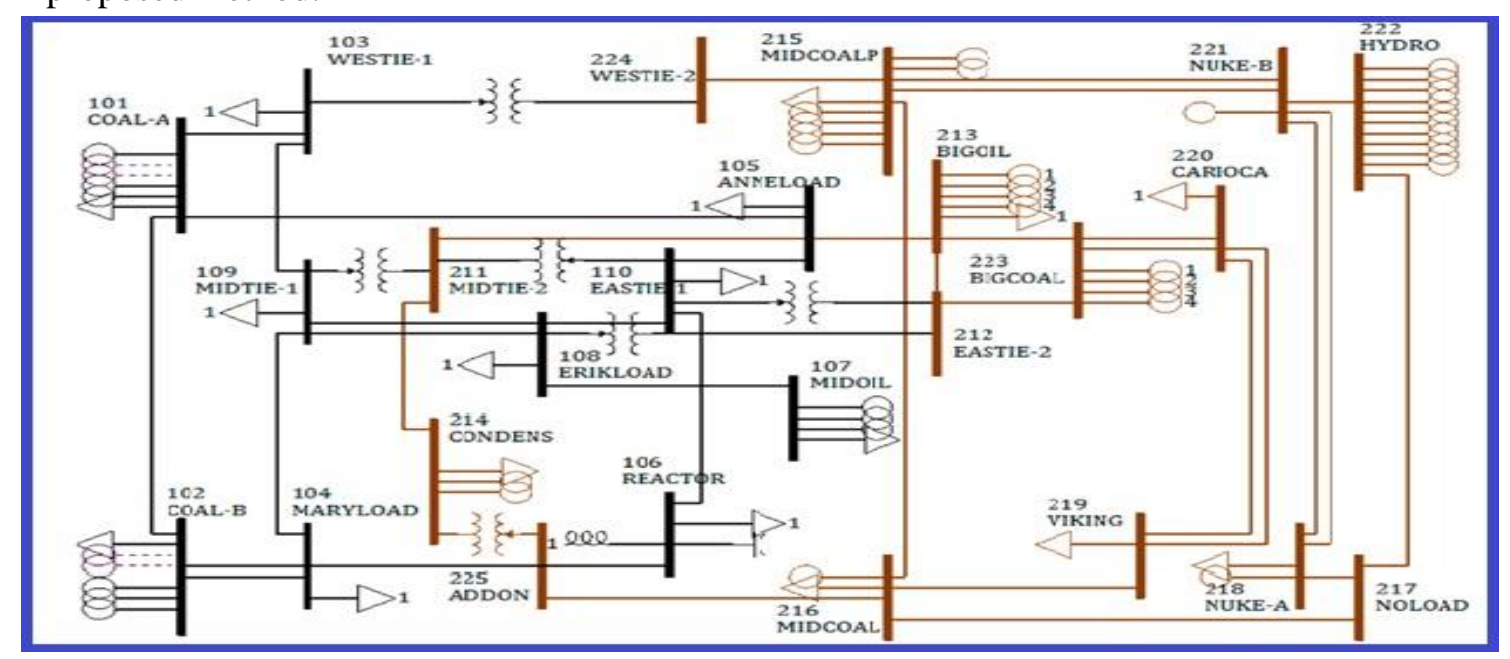

FIGURE 6. SLD OF IEEE 25-BUS

- Case (2): Practical System: Iraqi power grid is the practical system. Implementation the proposed method by using Iraqi power grid information at (8-1-2018) with PSS ${ }^{\mathrm{TM}}$ E version30.3 Package Program.

\section{SIMULATION AND RESULTS}

Case 1: - For Test System: The proposed method procedure was in section (4) mention above: -

a) Checking load flow analysis for the grid using Newton Raphson load flow technique.

b) Obtaining fault feeding currents table for branches of faulted busbar at fault as shown in Table 1.

Table 1. Currents Feeding 211 Busbar at Fault.

\begin{tabular}{ccccc}
\hline & \multicolumn{2}{c}{ Bus 211 MIDTIE-2 } & & \multicolumn{2}{c}{ Three Phase Fault } \\
Bus No. & Station Name & Voltage kV & $|\mathbf{I}|$ & $\mathbf{\theta}^{\mathbf{o}}$ \\
\hline 213 & BIGOIL & 230.00 & 1.3549 & -14.2559 \\
110 & EASTIE-1 & 138.00 & 1.6613 & -12.697 \\
109 & MIDTIE-1 & 138.00 & 1.7229 & -12.9896 \\
214 & CONDENS & 230.00 & 1.132 & -13.1707 \\
& Total Fault Current (P.U) & 5.8712 & -53.1132 \\
\hline
\end{tabular}

Checking load flow analysis for the (SBHSCL) and determining the position of SCCL device choices in Fig. 7, at series with transmission lines having the highest short circuit current feeding at fault. 


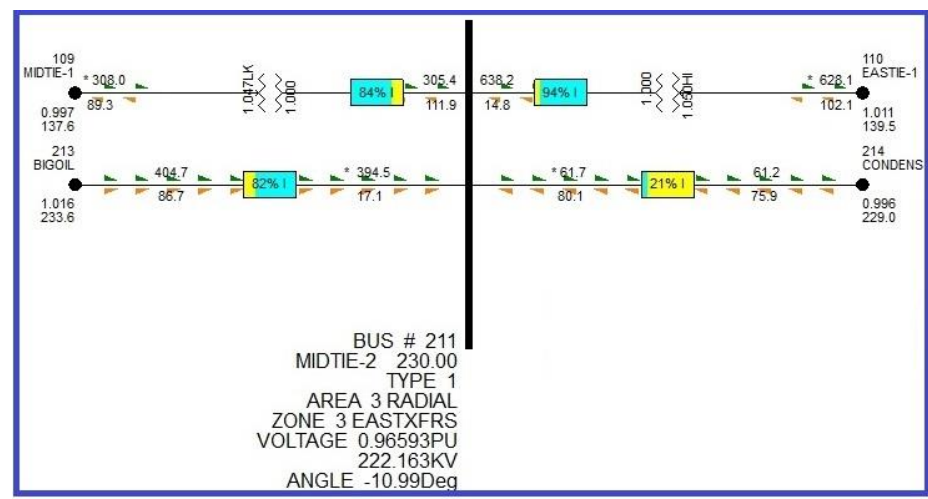

FIGURE 7. BUS \#211 MIDTIE-2 LOAD FLOW ANALYSIS.

a) Obtaining a table for the choices, as illustrated in Table2.

TABLE 2. THREE PHASE SHORT CIRCUIT LEVELS FOR IEEE 25-BUS SYSTEM WITH ADDING SERIES SCCL DEVICE WITH TRANSMISSION LINE.

\begin{tabular}{ccccc}
\hline \multicolumn{1}{c}{ SUBSTATION NAME } & & 211 MIDTIE-2 & 212 EASTIE-2 & 213 BIGOIL \\
\hline ORIGIN & $/ \mathrm{I} /$ & 5.8712 & 5.7595 & 3.517 \\
& $\Theta$ & -53.1132 & -50.2766 & -87.7821 \\
FACTS in 211-213 line with XL0.0594PU & $/ \mathrm{I} /$ & 5.0467 & 5.6936 & 2.8796 \\
& $\Theta$ & -47.0462 & -49.1607 & -84.5438 \\
FACTS in 211-213 line with XL0.1594PU & /I/ & 4.8901 & 5.7042 & 2.6953 \\
& $\Theta$ & -44.2334 & -48.564 & -82.8335 \\
\hline
\end{tabular}

b) Drawing curves for successful choices, as shown in Fig. 8 .

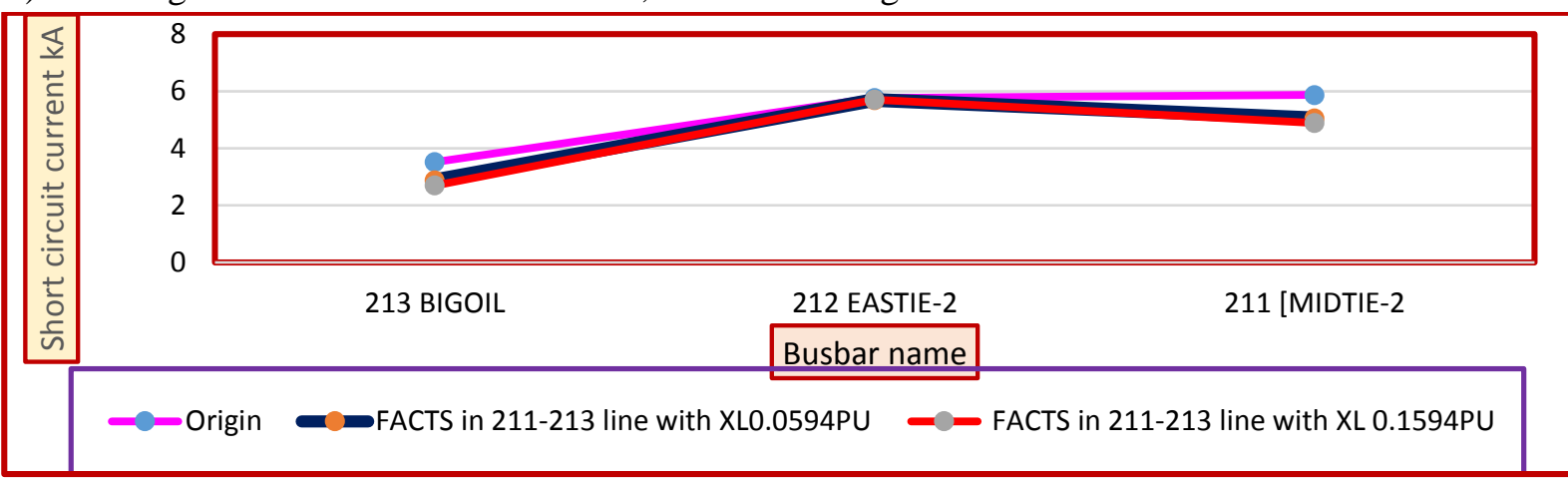

FiguRE 8. THREE PHASE SHORT CIRCUIT LEVELS FOR IEEE 25-BUS GRID BY ADDING SCCL DEVICE BETWEEN 211-213 LINE.

c) The best choice is by adding SCCL device in 211-213 line with a series reactive impedance $X=0.1594$ P.U. reduced the short circuit levels at minimum values for (SBHSCL) and other stations of the grid. Case 2: The practical system: By using the same procedure in item (4) with (PSS ${ }^{\mathrm{TM}} \mathrm{E}$ version 30.3 Package Program, the following points are considered:-

a) Using Newton Raphson load flow technique for checking load flow analysis of Iraqi power grid with flat condition.

b) Performing short circuit levels analysis for the grid busbars, and identifying the (SBHSCLs). The SBHSCLs are (400 kV power stations ((BSMG-1) (Basmayah)), ((KUTP) (Kut)) and (MUSP) (Musaiab Hydro-power station)) and 400kV substations ((4BGE) (Baghdad East)), ((BAB) (Babil)). 
Furthermore the highest are the $400 \mathrm{kV}$ substations ((4AMN) AL-Ameen) and ((4BGS) (Baghdad South)).

c) Obtaining a table for three short circuit current feeding faults for SBHSCL busbar feeders during fault.

d) Obtaining the flow diagram with load flow of the_(SBHSCL), as in Fig. 9 and determining the appropriate location of adding SCCL device in series with a power transmission line having the highest value.

e) Checking load flow and short circuit analysis for each choice.

f) Making a table for the successful choices for adding SCCL device in series with the 400KV BSMGAMN power transmission line with variable SCCL capacitive reactance values, as illustrated in Table 5.

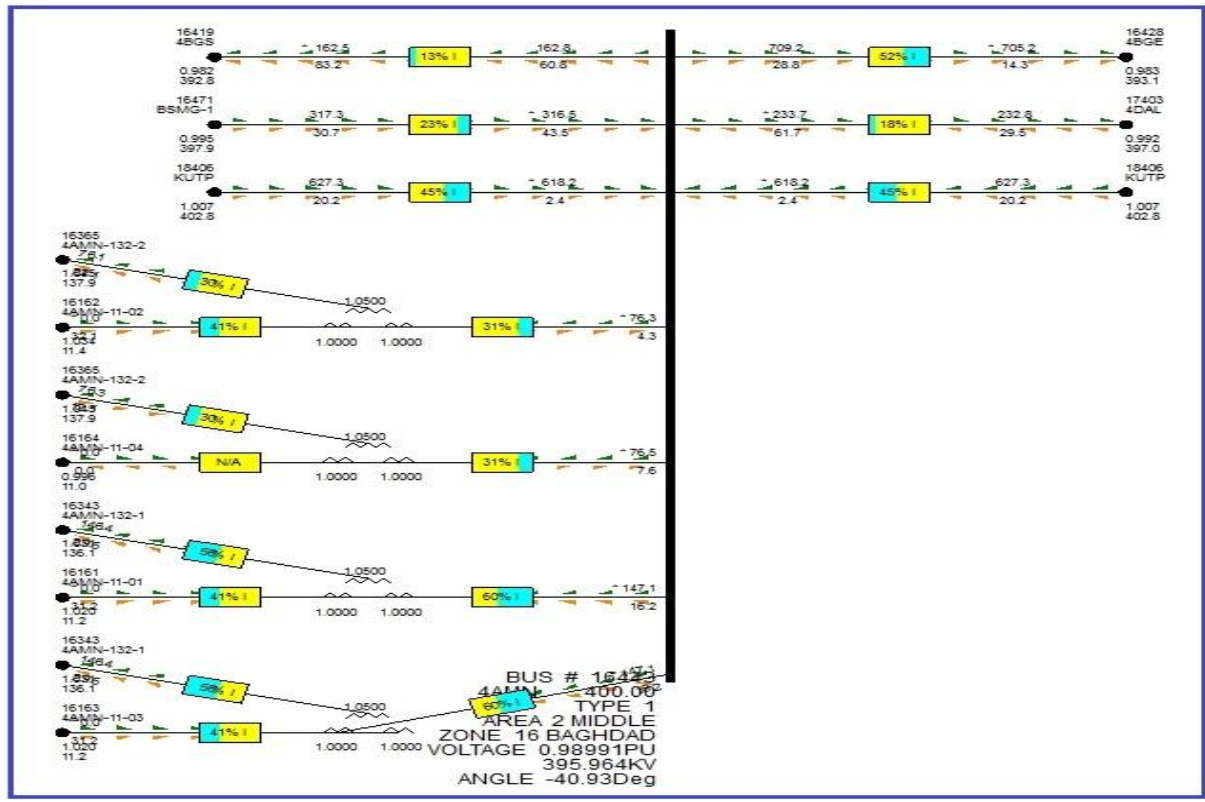

Figure 9. 400KV Al-Ameen Substation with LoAd Flow anAlysis.

Table 5. Three Phase Short Circuit Levels For AdDing ONE SCCL DeVice IN BSM-AMN device Lines

\begin{tabular}{ccccc}
\hline Substation & & 4BGS & [4AMN] & BSMG \\
\hline Origin & $|\mathrm{I}|$ & 31862 & 32576.5 & 31052 \\
& $\Theta$ & -86.11 & -86.07 & -86.48 \\
Line self reactor with Capacitor of & $|\mathrm{I}|$ & 27366.8 & 15296.2 & 12423.2 \\
(-0.0074PU) in BSM-AMN LINE & $\Theta$ & -73.14 & -43.32 & -41.78 \\
Line self reactor with Capacitor of & $|\mathrm{I}|$ & 27161.5 & 15219.8 & 12401.9 \\
(-0.0075PU) in BSM-AMN LINE & $\Theta$ & -73.9 & -45.84 & -44.46 \\
Line self reactor with Capacitor of & $|\mathrm{I}|$ & 26742.9 & 15427.2 & 12755.5 \\
(-0.008PU) in BSM-AMN LINE & $\Theta$ & -77.37 & -56.34 & -55.58 \\
Line self reactor with Capacitor of & $|\mathrm{I}|$ & 27181.8 & 16939.7 & 14311.7 \\
(-0.009PU) in BSM-AMN LINE & $\Theta$ & -81.59 & -68.6 & -68.53 \\
Line self-reactor with Capacitor of & $|\mathrm{I}|$ & 27824.4 & 18480.5 & 15846.1 \\
(-0.01PU) in BSM-AMN LINE & $\Theta$ & -83.5 & -74.53 & -74.8
\end{tabular}

- For adding SCCL device in series with the 400KV BSMG-BGS power transmission line with variable SCCL capacitive reactance values, as illustrated in Table 6. 


\begin{tabular}{ccccc}
\hline Substation & & 4BGS & 4AMN & BSMG1 \\
\hline Origin & $|\mathrm{I}|$ & 31862 & 32576.5 & 31052 \\
& $\Theta$ & -86.11 & -86.07 & -86.48 \\
Line self reactor with Xc=-0.012989PU in BSM-BGS LINE & $|\mathrm{I}|$ & 6848.6 & 28920.5 & 3290.5 \\
Line self reactor with Xc=-0.013989PU in BSM-BGS LINE & $\Theta$ & -45.64 & -83.59 & -47.77 \\
Line self reactor with Xc=-0.014989PU in BSM-BGS LINE & $-\mathrm{I} \mid$ & 8953.1 & 29129.6 & 4561.7 \\
& $-1 \mathrm{I}$ & 10836.9 & 29372.2 & 5768.5 \\
\hline
\end{tabular}

- For adding SCCL device in series with the $400 \mathrm{kV}$ BSMG-AMN and BSMG-BGS power transmission lines with variable SCCL capacitive reactance values, as illustrated in Table 7.

TABLE 7. THREE-PHASE SHORT CIRCUIT LEVELS COMPARISON BETWEEN ADDING SCCL DEVICE IN BSM-AMN AND BSMG-BGS AND TWO SCCL DEVICES IN THE TWO TRANSMISSION LINES.

\begin{tabular}{ccccc}
\hline Substation & & 4BGS & 4AMN & BSMG1 \\
\hline Origin & $|\mathrm{I}|$ & 31862 & 32576.5 & 31052 \\
& $\Theta$ & -86.11 & -86.07 & -86.48 \\
Line self reactor with Xc of (-0.015989PU) in BGSBSM line and & $|\mathrm{I}|$ & 110490 & 39762 & 9256.9 \\
line self reactor with Xc of (-0.066351PU) in AMN BSM LINE & $\Theta$ & -72.1 & -82.47 & 77.85 \\
Line self reactor with Xc of (-0.025989PU) in BGS BSM line and & $|\mathrm{I}|$ & 4652.6 & 9723.3 & 714.5 \\
line self reactor with Xc of (-0.066351PU) in AMN BSM LINE & $\Theta$ & 27.56 & 16.69 & 27.17 \\
Line self reactor with Xc of (-0.025989PU) in BGSBSM line and & $|\mathrm{I}|$ & 3601.2 & 7253.2 & 620.1 \\
line self reactor with Xc of (-0.076351PU) in AMN BSM LINE & $\Theta$ & -12.07 & -21.27 & -13.34 \\
Line self reactor with Xc of (-0.035989PU) in BGSBSM line and & $|\mathrm{I}|$ & 12669.8 & 17486.2 & 3246.5 \\
line self reactor with Xc of (-0.086351PU) in AMN BSM LINE & $\Theta$ & -80.55 & -82.65 & -83.67 \\
\hline
\end{tabular}

g)Drawing the curves for all choices in item 6 as follows: -

- For adding SCCL device in series with the 400kV BSMG-AMN power transmission line with variable SCCL capacitive reactance values illustrated in Fig. 10. From the curves, the best choice is for SCCL of capacitive and reactor impedance of (-0.008PU).

- For adding SCCL device in series with the 400KV BSMG-BGS power transmission line with variable SCCL capacitive reactance values, as illustrated in Fig. 11. From the curves, the best choice is for SCCL of capacitive and reactor impedance of $\mathrm{Xc}=-0.012989 \mathrm{PU}$.

- For adding SCCL device in series with 400KV BSMG-AMN and BSMG-BGS power transmission lines with variable SCCL capacitive reactance values, as illustrated in Fig. 12. From the curves, the best choice is for SCCL of capacitive and reactive impedance of (-0.076351PU) for the 400KV BSM-AMN power transmission line and the best choice is for SCCL of capacitive and reactive impedance ($0.025989 \mathrm{PU}$ ) of the 400KV BSM-BGS power transmission line. 


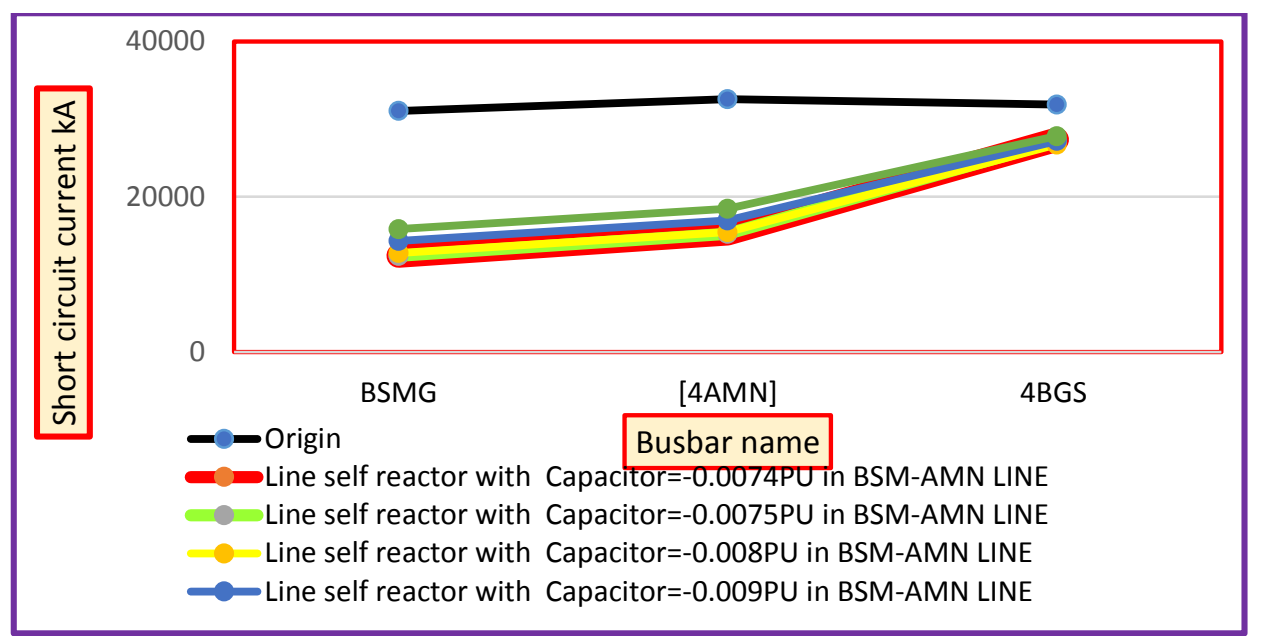

Figure 10.Three Phase Short Circuit Levels For AdDing SERIEs SCCL DEVICE With BSM-AMN linEs.

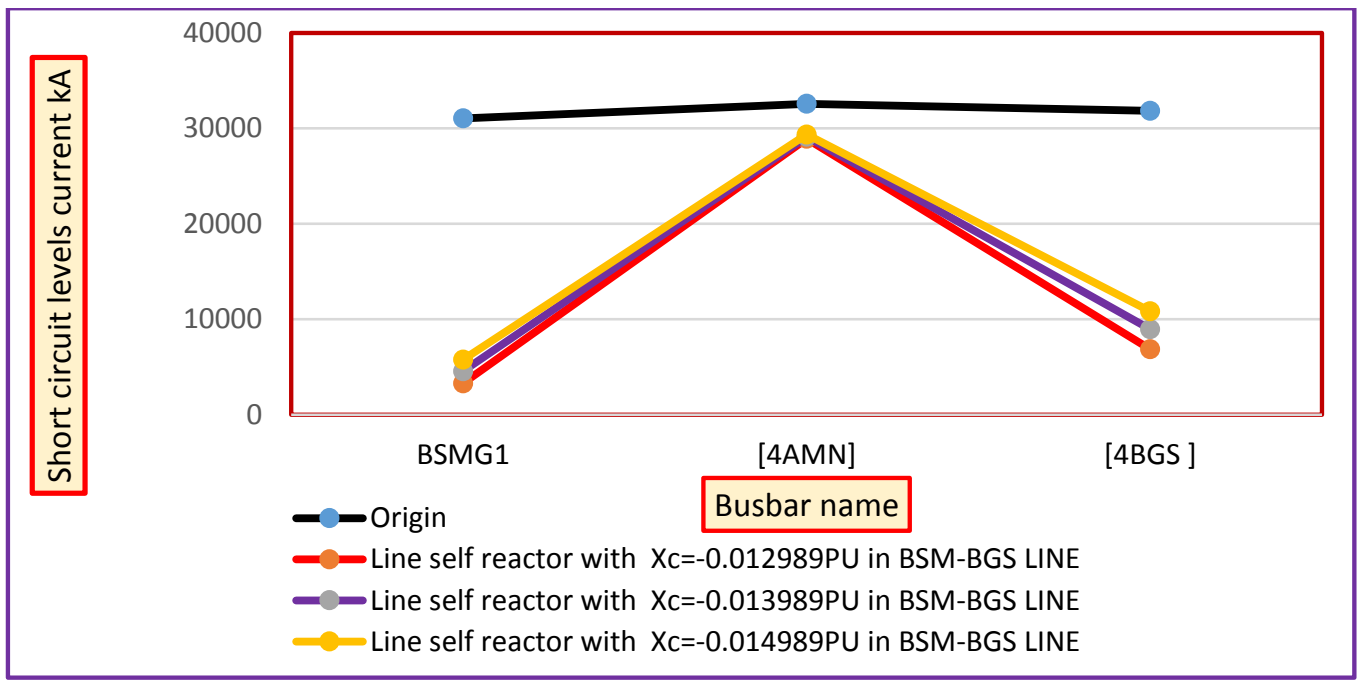

Figure 11. THREE PHASE SHORT CIRCUIT LEVELS FOR ADDING SCCL DEVICE IN BSMG-BGS DEVICE LINES.

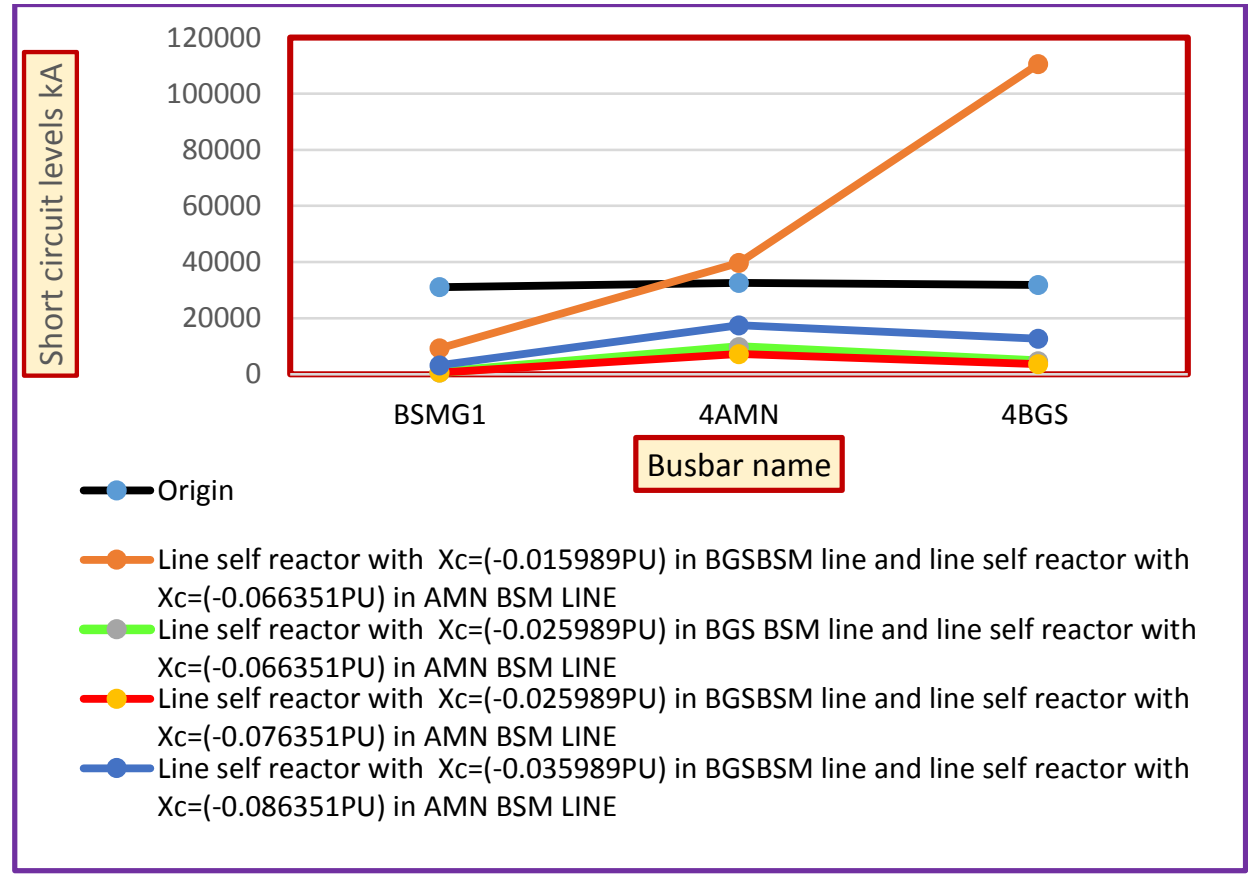

FIGURE 12. THREE PHASE SHORT CIRCUIT LEVEL FOR ADDING TWO SCCL DEVICESIN SERIES WITH 400KV BSM-AMN AND BSMG-BGS LINES. 
h) Making a comparison for the best choices of adding SCCL device on 400KV BSMG-AMN power transmission line, $400 \mathrm{KV}$ BSMG-BGS power transmission line and for the two power transmission lines, as given in Table9 and the curves of Fig.13.

TABLE 9. ADDING SCCL DEVICE ON 400KV BSM-AMN POWER TRANSMISSION LINE, 400KV BSM-BGS POWER TRANSMISSION LINE AND FOR THE TWO POWER TRANSMISSION LINES

\begin{tabular}{ccccc}
\hline Substation & & 4BGS & 4AMN & BSMG \\
\hline Origin & $/ \mathrm{I} /$ & 31862 & 32576.5 & 31052 \\
& $\Theta$ & -86.11 & -86.07 & -86.48 \\
Line self reactor with capacitor X=-0.008PU in BSM-AMN LINE & $/ \mathrm{I} /$ & 26742.9 & 15427.2 & 12755.5 \\
Line self reactor with Xc=-0.012989PU in BSM-BGS LINE & $\Theta$ & -77.37 & -56.34 & -55.58 \\
& $/ \mathrm{I} /$ & 6848.6 & 28920.5 & 3290.5 \\
Line self reactor with Xc=(-0.025989PU) in BGSBSM line and line & /I/ & -45.64 & -83.59 & -47.77 \\
self reactor with Xc=(-0.076351PU) in AMN BSM LINE & $\Theta$ & -12.07 & -21.27 & -13.34 \\
\hline
\end{tabular}

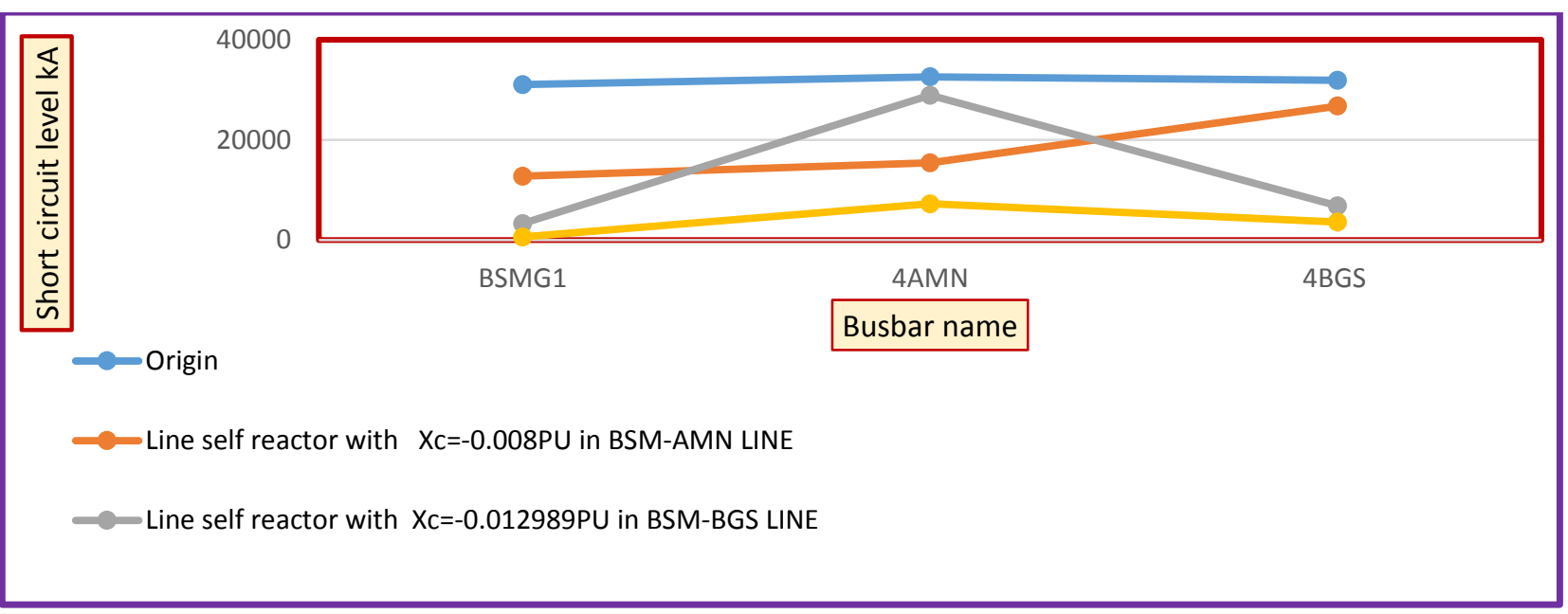

FIGURE 13. THREE PHASE SHORT CIRCUIT LEVELS COMPARISON CURVE FOR ADDING SCCL DEVICE.

From Fig. 13, it can be concluded that the optimum choice is by adding two SCCL devices, such that the first one with $400 \mathrm{kV}$ BSMG-AMN power transmission line which has reactive and capacitive impedance of (-0.076351PU) and the second with 400kV BSMG-AMN power transmission line which has reactive and capacitive impedance of (-0.025989PU). But if the cost is important compared with the values of short circuit levels, then the best choice will be adding one SCCL device with reactive and capacitive impedance of (-0.012989PU).

\section{CONCLUSION}

The conclusion from previous details through the study of the schedules and curves gives the following items:-

a) adding SCCL device depends on some items:

- The SBHSCLs locations and their switchyards connections.

- The fault power of branches.

- The load flow tests of the overall grid after adding series SCCL device.

b) The number of adding SCCL devices with the system depends on the amount of short circuit levels reduced, overall grid load flow test and cost.

c) The cost of adding SCCL devices compared with the cost of rehabilitation of the stations possesses 
high short circuit levels, making it an acceptable cost.

d) Comparing the result of adding series SCCL device strategies with splitting busbar or isolating islands strategies or adding series CLR strategies indicates that adding series SCCL device with transmission lines is the optimum choice for reducing short circuit levels.

\section{ACKNOWLEDGMENT}

The authors would like to thank Operation and Control Office, Planning and Studies Office, Training and Energy Researches Office and General Directorate for Electrical Energy Transportation of Middle Euphrates Region which are belonged to Ministry of Electricity of Iraq and the Department of Electrical Engineering, University of Technology for supporting information and all efforts.

\section{REFERENCES}

[1] M. Mohaddes, K. Sadek, D.P. Brandt and M.M. Rashwan, "Application of the Grid Power Flow Controller in a Back-to-Back Configuration", CIGRE Report B4-307, Session 2004.

[2] Ram Parashar, Leslie Al-Kingham, Robin Banks and Christian Sasse, " Fault Current Limiters for Transmission \& Distribution Networks ", CIRE(D 18th International Conference on Electricity Distribution Turin), AREVA T\&D Technology Centre, United Kingdom, 6-9 June 2005.

[3] Donal O'Leary and Klaus Habur, " FACTS (Flexible Alternating Current Transmission Systems) For Cost Effective and Reliable Transmission of Electrical Energy", Power Transmission and Distribution Group (EV) of Siemens AG in Erlangen, Germany,2001.

[4] L. Kirschner, K. Sadek and L., J. Bohn, “ Thyristor protected Series Capacitor (Part 1) Design Aspects ”, IEEE, T\&D Conference, Brazil, 2002.

[5] Lei, “Advanced Fully digital TCSC Real-Time Simulation”, Rio de Janeiro, Brazil, IPST 01, (24-28 June), 2001, June 2001.

[6] N. G. Hingorani, "Flexible AC Transmission", IEEE Spectrum, pp. 40-45, April 1993.

[7] J. M. Pina, T. Silva, A. P. Arsénio, Pronto, and P. Pereira, "Modelling and Simulation of Inductive Fault Current Limiters", Physics Procedia, vol.36, (pp. (1248-1253)), 2012.

[8] Enrique Acha, Cesar Angeles-Camacho, Hugo Ambriz-Pe'rez and Claudio R. Fuerte-Esquivel," FACTS Modelling and Simulation in Power Networks", John Wiley \& Sons Ltd, West Sussex PO19 8SQ, Southern Gate, the Atrium, Chichester, England, 2004.

[9] S. Geeves, R. Witzmann, D. Retzmann and K. Bergmann, "Improvement of System Stability by the Harker Static Var Compensators/UK Verification of System Performance by Digital and Real-Time Simulation ”, Beijing, China, ICPST 94, 18-21, Oct. 1994.

[10]V Gor, G Thumm, Lu Yi Chuan, D Retzmann, E Lerch, K Sadek and D Povh, "SCCL a new type of FACTS based short-circuit current limiter for application in high voltage systems", pp.204-209, GIGRE Session 2004, 2004.

[11] Song Han, Yong Chang and Xue-yan Mao," A Study on Modeling of High-Voltage Short Circuit Current Limiter in Electromechanical Transient Simulation", International Conference on Power System Technology, 2010.

[12] R.N. Nayak, Y.K. Sehgal and Subir Sen, "Series Compensation on 400kV Transmission Line -A Few Design Aspect", National Power System Conference NPSC 2004,Indian Institute of Technology, MADRAS 600 036 DEC.27-30, 2004.

[13]C. A. Ruiz, J. F. Gutierrez, and N. J. Orrego, “ The Colombian 2007 black out ”, Transmission and Distribution Conference and Exposition: Latin America 2008 IEEE/PES, Bogota, Colombia, 2008, (pp. 1-5), 2008.

[14] Narayana Prasad Padhy and Sidhartha Panda, "MATLAB SIMULINK Based Model of Single-Machine Infinite-Bus with TCSC for Stability Studies and Tuning Employing GA", Computer, Energetic World Academy of Science, Engineering and Technology International Journal of Electrical, , Electronic and Communication Engineering, (Vol.1), (No. 3), 2007.

[15] A. J. Phillips, X. Z. Qiu, R. Mercinelli , M. Valvo , P. Vaes, P. J. Vetter, , M. O. van Deventer, C. M. Martin and J. M. Senior," Redundancy Strategies for a High Splitting Optically Amplified Passive Optical Network", Journal of Light wave. Technology, (Vol.19), (No.2), February 2001.

[16] Heresh Seyedi, Barzan Tabei, "Appropriate Placement of Fault Current Limiting Reactors in Different HV Substation Arrangements", Faculty of Electrical and Computer Engineering, University of Tabriz, Tabriz, Iran. May 2012.

[17] Rajiv K. Varma and R. Mohan Mathur," Thyristor-Based FACTS Controllers for Electrical Transmission Systems", John Wiley \& Sons, (ISBN: 0-471-20643-1), Inc. Publication, 2002.

[18] Abdelaziz Chaghi and Mohamed Zellagui, " Impact of Series FACTS Devices GCSC, TCSC and TCSR on Distance Protection Setting Zones in 400 kV Transmission Line ", LSP-IE Research Laboratory, INTECH, Faculty of Technology, University of Batna, Department of Electrical Engineering, Algeria, 2013.

[19]Erik Darnell Johnson."A Silicon Carbide Based Solid-State Fault Current Limiter for Modern Power Distribution Systems", ScholarWorks@UARK, University of Arkansas, Fayetteville. University of Arkansas, Fayetteville, Theses and Dissertations. 585, 12, 2012..

[20] Wang Xiaohui, Yu Yinghui and Yang Zenghui,"Study of the application of TPSC based short-circuit current limiter in East China Power Grid", East China Electric Power, (pp. 11-14), (no. 5), (vol. 33) ,2005. 